ISSN 2447-9071

doi 10.36414/rbmc.v5i12.12
Contato para correspondência:

Antonio Márcio Teodoro Cordeiro Silva

E-mail:

marciocmed@gmail.com

Conflito de interesse: Não

Financiamento: Recursos próprios

Recebido: 30/06/2019

Aprovado: 03/08/2019

\section{A inibição da telomerase em oncócitos: o fim da imortalidade celular}

\author{
Inhibition of telomerase in oncocytes: the end of cellular \\ immortality
}

Laise Duanne Gomes da Silva', Daiane de Oliveira Cunha², Jacqueline Andréia Bernardes Leão Cordeiro ${ }^{3}$, Xisto Sena Passos ${ }^{4}$, Fábio Silvestre Ataides ${ }^{5}$, Cesar Augusto Sam Tiago Vilanova-Costa ${ }^{6}$, Antônio Márcio Teodoro Cordeiro Silva ${ }^{7}$

'Biomédica, Universidade Paulista - UNIP, ${ }^{2}$ Biomédica, Mestre em Ciências Ambientais e Saúde, Pontifícia Universidade Católica de Goiás - PUC-Goiás, Goiânia, Goiás, Brasil, ${ }^{3}$ Enfermeira, Doutora em Enfermagem, Professora da Faculdade de Enfermagem da Universidade Federal de Goiás, ${ }^{4}$ Biólogo, Doutor em Medicina Tropical pela UFG, Professor da Universidade Paulista - UNIP, ${ }^{5}$ Biomédico, Doutor em Medicina Tropical, Professor do curso de Biomedicina da PUC Goiás e da UNIP, 'BBiólogo, Doutor em Ciências Biológicas, Laboratório de Biologia Tumoral e Oncogenética do Hospital Araújo Jorge, 'Biomédico, Doutor em Biologia Celular e Molecular, Professor do Curso de Medicina e do Programa de Pós-Graduação em Ciências Ambientais e Saúde da PUC Goiás.

\section{Resumo}

A imortalidade celularéuma característica marcante da célula tumoral. Aproximadamente, $90 \%$ das linhagens dessas células reativamo gene silenciado da enzima telomerase para adquirirem tal atributo e se proliferarem de maneira descontrolada. O objetivo desse trabalho foi identificar se à inibição da enzima telomeraseéummecanismo contra i imortalidade de células tumorais. Trata-se de umarevisão de literatura narrativa. As buscas das referências bibliográficas foram feitas nas bases de dados: Lilacs, SciELO, PubMed, utilizando os descritores:telomerase, inibição da telomerase, telômerosecâncer, com seus correspondentes em inglês. O uso de inibidores diretos da telomerase como terapia antitumoral, exemplo GRN160L, em estudos pré-clínicos apontou uma redução na proliferação e morte de células tumorais. Porém, em alguns ensaios só apresentaram efeitos terapêuticos após a célula sofrerencurtamento crítico de telômeros. Terapias que promovem disfunções nos telômeros para dificultaroacesso da enzima ao substrato telomérico, demonstram sercapazes de induzirrespostade dano ao DNA emorte celular mais rápida. Considerando a alta reativação da telomerase em tumorigêneses é evidente que ela pode ser um mecanismo potencial contra a imortalidade celular. Assim, os avanços de estudos em andamento possibilitarão melhor elucidação dos fatos e maior consolidação para futuras pesquisas.

Palavras-Chave: Telomerase, Telômero, Câncer, Carcinogênese.

\begin{abstract}
Cellularimmortality is a hallmark of the tumorcell. Approximately $90 \%$ of these cell lines reactivate the mutated gene of theenzymetelomerase to acquire such an attribute and proliferate in an uncontrolled manner. The objective of this work was to identify whether the inhibition of the enzyme telomerase is a mechanism against the immortality of tumor cells. This is a review of narrative literature. The bibliographical references were searched in the following databases: Lilacs, SciELO, PubMed, using the descriptors: telomerase, inhibition of telomerase, telomeres and cancer, with their correspondents in English. The use of direct telomerase inhibitors as an antitumor therapy, eg GRN160L, in preclinical studies has pointed to a reduction in tumor cell proliferation and death. However, in some trials only showed therapeutic effects after the cell undergoes critical shortening of telomeres. Therapies that promote telomere dysfunction to hinder the enzyme's access to the telomeric substrate, are shown to be capable of inducing DNA damage response and faster cell death. Considering the high reactivation of telomerase in tumorigenesis it is evident that it may be a potential mechanism against cellular immortality. Thus, advances in ongoing studies will enable better elucidation of the facts and greater consolidation for future research.
\end{abstract}

Palavras-Chave: Telomerase, Telomere, Cancer, Carcinogenesis. 


\section{Introdução}

A enzima telomerase é um complexo ribonucleoproteína, que promove a manutenção do comprimento dos telômeros ao sintetizar as sequências repetitivas do DNA telomérico'. Os telômeros são regiões não codantes do genoma, localizados nas extremidades dos cromossomos, mas que desempenham um importante papel na manutenção e integridade do DNA2 ${ }^{2}$. O seu encurtamento, pode comprometer o potencial replicativo das células, contribuindo para a entrada destas, no processo natural de senescência celular ${ }^{3}$.

A telomerase está presente nos estágios iniciais do desenvolvimento humano. Mas, no período neonatal, a atividade da enzima é reduzida ou nula, ficando ausente na maioria dos tecidos somáticos ${ }^{4}$. Em decorrência disso, gradativamente a cada divisão celular os terminais teloméricos destas células são encurtados normalmente, chegando a um limite mínimo de tamanho que possibilite a divisão celular, denominado Hayflick ${ }^{5}$.

Porém, aproximadamente $90 \%$ das células somáticas cancerígenas, que alcançam a imortalidade celular, apresentam alta expressividade da telomerase ${ }^{6}$. A reativação do gene silenciado da telomerase, nessas células tumorais, tem sido um dos mecanismos utilizados para burlar o sistema natural de senescência celular e apoptose, permitindo assim que essas células continuem promovendo o alongamento dos telômeros e se repliquem de maneira descontrolada e ininterrupta ${ }^{7}$.

A elevada expressão da telomerase na maioria dos tipos de câncer tem tornando-a um alvo importante para o desenvolvimento de terapias anticancerígenas, que objetivam induzir, seletivamente, a apoptose nessas células, oferecendo um risco mínimo de encurtamento de telômeros em células normais ${ }^{8}$.

O presente estudo teve como objetivo avaliar a inibição da enzima telomerase como possível mecanismo contra a imortalidade de células tumorais.

\section{Revisão da Literatura}

Este trabalho trata-se de uma revisão narrativa de literatura sobre a inibição da telomerase como ferramenta potencial contra a imortalidade celular. As buscas das referências bibliográficas foram feitas nas respectivas bases de dados: Lilacs, SciELO, PubMed, utilizando os seguintes descritores: telomerase, inibição da telomerase, telômeros e câncer, como também seus correspondentes em inglês: telomerase, telomerase inhibition, telomeres e cancer. As referências consideradas para este estudo foram publicações que datam entre o período de 2012 a 2017, nos idiomas: português, inglês e espanhol.

\section{Descoberta dos telômeros e telomerase}

Em 1938, no Instituto de Genética Animal de Ediburgo, no Reino Unido, Hermann J. Muller, um geneticista estadunidense, ao expor moscas da espécie Drosophila melanogaster a raios $\mathrm{X}$, observou estruturas nas extremidades dos cromossomos que os tornavam resistentes a radiação. A estas estruturas, Muller nomeou de "telômeros".

Em 1941, Barbara McClintock, pesquisadora da Universidade de Missouri, descobriu que cromossomos "quebrados" eram instáveis, mas que estes, podiam ter suas extremidades novamente restauradas. Porém, até então, não se tinha conhecimento do mecanismo pelo qual ocorria a restauração ${ }^{10}$.

Quando a estrutura do DNA foi desvendada por Francis Crick, James Watson e Maurice Wilkins, o enigma da restauração dos telômeros tornou-se mais complexo, em virtude da descoberta da enzima que promove a replicação do DNA, a DNA-Polimerase. Watson verificou que a ação da DNA-Polimerase não permitia a replicação por completo da extremidade $3^{\prime}$ da fita descontínua ${ }^{11}$.

O cientista Russo, Alexsei Matveevich Olovnikov, postulou uma íntima ligação entre o problema de replicação da ponta 3' e o limite de divisão celular, descrito previamente por Leonard Hayflick. Segundo, o qual, a cada divisão, a célula sofre um encurtamento progressivo de suas extremidades, apontando para o processo de senescência celular ${ }^{5}$.

Em 1975, a investigadora Elizabeth Blackburn descobriu sequências repetitivas do hexanucleotídeo -CCCCAA- nas terminações do DNA do ciliado Tetrahymena thermophila. Na mesma época, Jack Szostak, geneticista da escola de medicina de Havard, desenvolvia um trabalho com o objetivo de construir cromossomos artificiais, compostos por genes humanos em uma só molécula linear de DNA. No entanto, os cromossomos de Szostak eram instáveis e não se replicavam pela ausência de telômeros ${ }^{12}$.

Blackburn e Szostak propuseram verificar o que aconteceria com a inserção das sequências repetitivas terminais -CCCCAA- da Tetrahymena aos plasmídeos de Szostak ${ }^{11}$. Como resultado desse processo, os plasmídeos passaram a se replicar de forma estável ${ }^{12}$.

Em Berkeley, na Faculdade da Califórnia, Elizabeth Blackburn e Carol Greider em um experimento, descobriram que a restauração dos telômeros se devia a atividade da enzima telomerase, um complexo de ribonucleoproteína independente, que utiliza o seu componente intrínseco de RNA com a sequência -CAACCCAA- como fita molde para a síntese das repetidas sequências terminais ${ }^{13}$.

\section{Estrutura e função dos telômeros}

Os telômeros são estruturas constituídas de dupla fita de DNA e proteínas, de comprimento variável, localizados na extremidade dos cromossomos de eucariotos. São extensões de sequências hexaméricas 5'TTAGGG3', que se repetem ao 
longo da cadeia telomérica. Em torno de sua parte terminal, os telômeros se associam a um complexo multiproteico, denominado de shelterin ${ }^{14}$.

O DNA telômerico termina com uma saliência ou protusão, de fita simples, rica em guanina na extremidade 3'. Esta extremidade 3 ' livre, de fita simples, além de servir como substrato para a adição de repetições teloméricas pela enzima telomerase, também irá servir como estrutura de proteção do DNA telomérico, ao assumir a conformação do T-loop, impedindo, por exemplo, a fusão das extremidades teloméricas, e o reconhecimento dos telômeros pela maquinária de resposta a danos no DNA ${ }^{2,15}$.

Os telômeros são essenciais para a manutenção e integridade do genoma, ao prevenirem a degradação, recombinação e fusão entre os cromossomos, além de serem fundamentais para a completa replicação do DNA de eucariotos, durante a divisão celular ${ }^{3}$.

\section{Estrutura e função da telomerase}

A telomerase é um complexo ribonucleoproteíco, composto por duas subunidades. A subunidade catalítica TERT (telomerase reverse transcriptase), e a outra subunidade TERC (telomerase RNA component). A TERT possui atividade de transcriptase reversa, promovendo a manutenção do comprimento dos telômeros, ao sintetizar as sequências repetitivas do DNA telomérico ${ }^{1,16}$. A outra subunidade (TERC) compõe-se de uma sequência de RNA, que constitui a sequência molde necessária para o alongamento do DNA telomérico ${ }^{16}$.

Para que ocorra a ligação da telomerase ao telômero, in vivo, e sua atividade catalítica seja desenvolvida, o complexo requer a ação de componentes proteicos do complexo shelterin, que auxiliam também na regulação da atividade da enzima'.

Proteínas específicas do complexo shelterin reconhecem a extremidade $3^{\prime}$ livre e se associam a ela, com o objetivo de estabilizar as extremidades cromossômicas, como também de promover o recrutamento da telomerase para a reposição das sequências teloméricas a cada divisão celular². A partir disso, a ponta $3^{\prime}$ livre é reconhecida pela telomerase e então, a enzima começa a adicionar repetições teloméricas a essa extremidade ${ }^{15}$.

A atividade catalítica da enzima se faz presente nos estágios iniciais do desenvolvimento humano. Mas, no período neonatal, naturalmente, a atividade da enzima é reduzida ou nula, ficando ausente na maioria dos tecidos somáticos4. A ausência da telomerase somada ao problema de replicação completa da extremidade $3^{\prime}$ da fita descontínua favorece o encurtamento dos telômeros e a senescência celular ${ }^{5}$.

\section{A reativação da telomerase e imortalidade celular em} oncócitos

A senescência replicativa ou fase de mortalidade 1 (M1) é demarcada pela interrupção de divisão celular. No entanto, algumas células ignoram a fase $M 1$, ao inativarem vias de verificação do ciclo celular, como por exemplo, a proteína p53 e/ou a p16, mantendo a divisão celular e gerando, consequentemente, telômeros muito curtos, que irão demarcar a fase de crise ou mortalidade 2 (M2), na qual, tem-se uma grande instabilidade genômica, eventos mutagênicos, resultando em intensa morte celular17. Nesse contexto, raramente algumas células ( 1 em 100.000 a 1 em 10 milhões) conseguem superar a crise e adquirir a imortalidade celular ${ }^{18}$. A fase de senescência replicativa e a crise celular são duas barreiras importantes contra a imortalidade celular e a transformação maligna ${ }^{19}$.

Os oncócitos sobrevivem e alcançam a imortalidade em aproximadamente $90 \%$ das linhagens celulares de câncer em humanos, aumentando ou reativando a expressão dos genes: hTERT, que codifica a subunidade catalítica da telomerase, e hTERC, codificador do componente RNA intrínseco da enzima6. Em um percentual menor, entre 10 a 15\% das células tumorais podem inverter o encurtamento crítico dos telômeros, para ignorar o processo de senescência, através do alongamento alternativo de telômeros (ALT), baseado na recombinação homóloga do DNA presente nessas regiões ${ }^{20}$.

A reativação do gene silenciado da telomerase nas células tumorais tem sido um dos mecanismos utilizados para burlar o sistema natural de senescência celular e apoptose, permitindo assim que essas células tumorais continuem promovendo o alongamento dos telômeros e se repliquem de maneira descontrolada e ininterrupta?.

\section{Princípios de algumas terapias anti-telomerásicas}

A elevada expressão da telomerase, na maioria dos tipos de câncer, tem tornaram a mesma um alvo importante para o desenvolvimento de terapias anticancerígenas, que objetivam induzir, seletivamente, a apoptose nessas células, oferecendo um risco reduzido de encurtamento de telômeros em células normais 8 .

Algumas estratégias que visam a inibição direta da enzima telomerase comprometem-se com o desenvolvimento de inibidores competitivos de sítios da enzima, com o objetivo de impedir formação do complexo ativo telomerásico ao inibir a associação das subunidades TERT e TERC da ribonucleoproteína, ou ainda a ligação desta ao substrato telomérico21. Vários inibidores de moléculas da telomerase foram desenvolvidos, dentre eles, se destacam os inibidores competitivos Imetelstat, conhecido também como GRN163L e o BIBR153222. 
O imetelstat é um oligonucleotídeo modificado que foi desenvolvido para ser administrado de forma intravenosa e para o tratamento de vários tipos de câncer ${ }^{23}$. Possui a sequência 5'TAGGGTTAGACAA3' que se associa a 13 nucleotídeos do modelo TERC, interrompendo a montagem da ribonucleoproteína (TERT + TERC) e sua atividade enzimática nos telômeros ${ }^{24}$. De maneira semelhante, o BIBR 1532 também impede a montagem da telomerase, porém faz isso, ao se ligar ao domínio TERT, interrompendo a associação TERT-RNA ${ }^{22}$.

Outras estratégias terapêuticas em desenvolvimento, para combater a imortalidade celular maligna, atuam em focos diferentes, como por exemplo, os telômeros, o sistema imune, os promotores TERT e TERC, entre outras ${ }^{25}$. Estratégias como os estabilizadores do G-quadruplex e inibidores Tnakyrase, tornam os telômeros inacessíveis a telomerase. O primeiro torna a extremidade $3^{\prime}$ inacessível ao impedir o desenrolamento do G-quadruplex e o segundo, ao inibir a dissociação entre a proteína TRF1, componente do complexo shelterin, dos telômeros ${ }^{25}$.

A imunoterapia antitelomerase, também em desenvolvimento, visa sensibilizar o sistema imunológico contra células tumorais que apresentam peptídeos ou epítopos antigênicos de telomerases degradadas por proteossomas, que são expressos na membrana celular tumoral positiva para telomerase via classe I do complexo de histocompatibilidade (MHC). Estes epítopos antigênicos podem induzir respostas $C D 4+$ ou CD8+ de linfócitos T citotóxicos específicas contra tumores positivo para telomerase ${ }^{26}$.

\section{Discussão}

O levantamento bibliográfico realizado com o objetivo de verificar a potencialidade da inibição da enzima telomerase contra a imortalidade celular em oncócitos, em decorrência de aproximadamente $90 \%$ das linhagens celulares de câncer, sobreviverem e alcançarem a imortalidade celular, aumentando ou reativando a expressão dos genes que codificam a telomerase 6, possibilitou verificar vários estudos em desenvolvimento que se engajam na perspectiva de inibir a imortalidade celular.

Inibidores da telomerase, a exemplo do Imetelstat ou GRN163L, o qual foi amplamente avaliado quanto a sua atividade e eficácia em estudos pré-clínicos contra várias linhagens de câncer, em modelos de xenogravagem em ratos, demonstraram provocar o encurtamento de telômeros em tumores de bexiga, fígado, pulmão, mama, pâncreas e próstata através de sua eficiente ação inibitória da telomerase ${ }^{24}$.

Um estudo avaliou os efeitos do GRN163L na atividade da telomerase em dez linhagens celulares de câncer de pâncreas, demonstrou que o GRN163L reduziu a proliferação e sobre- vivência celular somente após a célula sofrer o encurtamento crítico dos telômeros ${ }^{27}$. No final da vida útil das células tratadas com GRN163L, os telômeros tornaram-se criticamente curtos até o ponto de indetectabilidade e mais de $80 \%$ apresentaram c-H2AX, indicando presença de dsDNA-breaks, esperado para células em crise. Observou-se ainda que a eficácia da inibição telomerásica pelo GRN163L está associada ao seu tempo de vida útil, ou seja, a suspensão do GRN163L reverte a maioria dos efeitos, podendo proporcionar a célula à fuga da crise ${ }^{27}$.

Um estudo, ao discutir o período de atraso necessário para se observar o encurtamento crítico dos telômeros, o retorno à crise e a morte celular gerado por inibidores direto da telomerase, sugeriram que a inibição direta isolada da enzima pudesse ser ineficaz como tratamento autônomo, sugerindo uma combinação do tratamento de inibição direta com a radiação ionizante $(\mathrm{RI})^{28}$. Tal estudo desenvolveu um experimento in vitro, investigando a conjugação de três inibidores direto da telomerase, sendo eles, o BIBR-1532, um flavonóide (2-(3,4-di-hidroxifenil)-7,8-di-hidroxi-4H-cromen-4ona) e o MST-312 com agentes radioiodados- 123 e os seus respectivos efeitos inibitórios em células cancerígenas.

Dos três inibidores citados anteriormente, o 123I-MST-312 foi o mais estável, provocando radioatividade e morte celular dependente da concentração ${ }^{28}$. Até o momento, não houve ainda uma abordagem que prosseguiu os estudos dos efeitos da radiossensibilização utilizando inibidores direto da telomerase associados a agentes radiomarcados. As investigações limitam-se a fontes de radiação de feixes externos ${ }^{28}$.

Há um grande desafio para a terapia dirigida à inibição direta da telomerase, em decorrência do tempo de atraso requerido para se observar o encurtamento de telômeros e morte celular ${ }^{29}$. O tempo requerido, implica em uma série de ciclos de divisão celular, onde células tumorais continuarão a se replicar até que se tenha efeitos terapêuticos, sugerindo outra modalidade de tratamento de ação rápida que pode inibir a atividade da enzima indiretamente, para obtenção de resultados clínicos. Sugere-se a introdução de um nucleosídeo modificado na célula, para que este seja incorporado ao DNA telomérico, preferencialmente pela telomerase. Este nucleosídeo alterado nos telômeros, por não se associar de forma eficiente as proteínas que protegem o DNA, provocará uma disfunção nos telômeros, morte celular rápida, além de inibir indiretamente a atividade telomerásica ${ }^{29}$.

Um estudo, ao utilizar um 6-tio-2'-desoxiguanosina (6-thiodG), um nuclesídeo modificado, em células tumorais positivas para a telomerase, demonstraram que o mesmo é reconhecido e incorporado aos telômeros pela telomerase, formando telômeros alterados que induzem consequentemente res- 
postas de dano ao DNA e rápida morte celular. $O$ tratamento com 6-thio-Dg provocou rápida morte celular em oncócitos, enquanto que não se observou efeitos em fibroblastos humanos normais de telomerase negativa e nem em células normais do epitélio do cólon humano. Camundongos tratados durante um mês, com doses efetivas de 6-thio-dG, não demonstraram efeitos colaterais hepáticos, hematológicos e renais ${ }^{30}$.

Vale ressaltar que, apesar dos avanços significativos no conhecimento da função da telomerase no desenvolvimento de cânceres, não existe ainda agentes antitelomerásicos aprovados para uso clínico 25 .

\section{Conclusão}

Ao longo dos anos, o conhecimento sobre os telômeros e a telomerase melhorou notavelmente. A compreensão dos mecanismos envolvidos na reativação e recrutamento da telomerase para expandir a capacidade proliferativa de células cancerosas possibilitou a criação de várias ferramentas terapêuticas anticancerígenas, em especial as que promovem a inibição direta da telomerase ou as que buscam dificultar seu acesso aos telômeros, inibindo-a indiretamente.

Ensaios clínicos com inibidores diretos da telomerase, demonstraram que a mesma é um alvo viável contra a imortalidade celular, mas apontaram um intervalo de tempo longo para que se obtenha efeitos clínicos. Este aspecto não é positivo, visto a alta capacidade de proliferação e metástases dos oncócitos. Por outro lado, observou-se uma relativa concordância entre autores de que as terapias baseadas em promover alterações nos telômeros ou na relação deste com proteínas associadas a ele, parecem ser mais eficazes, por disparar resposta de dano ao DNA e morte celular mais rápida. Nesse sentido, os avanços de estudos que estão em andamento trarão uma melhor elucidação dos fatos e uma maior consolidação para futuras pesquisas.

\section{Agradecimentos}

Este trabalho foi financiado pela Fundação de Amparo à Pesquisa do Estado de Goiás - FAPEG.

\section{Referências Bibliográficas}

1. Zhou J, Ding D, Wang M, Cong Y-S. Telomerase reverse transcriptase in the regulation of gene expression. BMB Rep. 2014;47(1):8-14.

2. Wang C, Zhao L, Lu S. Role of TERRA in the regulation of telomere length. Int J Biol Sci. 2015;11(3):316-23.

3. Lange T. How shelterin solves the telomere end-protection problem. cold spring harb symp quant Biol. 2010;75:167-77. 4. Perez A, Castillo FG, Moreno JG. A non-canonical function of telomerase RNA in the regulation of developmental myelo- poiesis in zebrafish. Nat Commun. 2014;5:3228.

5. Chuaire L. Telomeros y Telomerasa: Breve recuento de una historia iniciada por Hermann Muller y Barbara McClintock. Colomb Med. 2006;37(4):332-5.

6. Shay JW. Are short Telomeres predictive of advanced cancer? NIH Public Access. 2013;3(10):1096-8.

7. Griffiths AJF. Introdução à Genética. 10a edição. Edditora Guanabara, editor. 2013.

8. Buseman C, Wright WE, Shay JW. Is telomerase a viable target in cancer? Mutat Res. 2012;730(1):90-7.

9. Muller HJ. The Remaking of chromosomes. Collect net. 1938;13:181-98.

10. McClintock B. The stability of broken ends of chromosomes in zea mays. Genetics. 1941;26(2):234-82.

11. Jardim LB, Maluf SW. O prêmio Nobel de Fisiologia e Medicina de 2009: O papel dis telômeros e da Telomerase na manutenção dos Cromossomos. Rev HCPA. 2009;29(2):271-5. 12. Birmingham K. Elizabeth Blackburn. Nat Med. 2001;7(1):520. 13. Greider CW, Blackburn E. A telomeriic sequence in the RNA of Tetrahymena telomerase required for telomere repeat synthesis. Nature. 1989;26:331-7.

14. Rojas CC, Shippen DE. Telomerase regulation. Mutat Res. 2012;730(1-2):20-7.

15. Stewart JA, Wang F, Chaiken MF, Kasbek C, li PDC, Wright $W E$, et al. Human CST promotes telomere duplex replication and general replication restart after fork stalling. EMBO J. 2012;31(17):3537-49.

16. Lemos CA. Aspetos estruturais e funcionais do complexo telómero / telomerase. Universidade Fernando Pessoa; 2015. 17. Hayashi MT, Cesare AJ, Rivera T, Karlseder J. HHS Public Access. Nature. 2015;522(5):492-6.

18. Vega LJC, Jouravleva K, Ortiz-Montero P, Liu WY, Galeano JL, Romero $\mathrm{M}$, et al. The senescent microenvironment promotes the emergence of heterogeneous cancer stem-like cells. Carcinogenesis. 2015;36(10):1180-92.

19. Wright WE, Pereira-Smith OM, Shay JW. Reversible cellular senescence: implications for immortalization of normal human diploid fibroblasts. Mol Cell Biol. 2015;9(7):3088-92.

20. Dilley RL, Greenberg RA. HHS Public Access. Trends Cancer. 2015;1(2):145-56.

21. Marian CO, Wright WE, Shay JW. The effects of telomerase inhibition on ptostate tumor-initiating cells. Int J Cancer. 2010;127(2):321-31.

22. Bryan C, Rice C, Hoffman H. HHS Public Access. structure. 2015;23(10):1934-42.

23. Jackson SR, Zhu CH, Paulson V. Antiadhesive effects of GRN163L- an Oligonucleotide N3'>p5' thio-phosphoramidate targeting telomerase. Cancer Res. 2007;67(3):1121-9. 
24. Hu Y, Bobb D, He J, Hill DA, Dome JS. The HSP90 inhibitor alvespimycin enhances the potency of telomerase inhibition by imetelstat in human osteosarcoma. Cancer Biol Ther. 2015;16(6):949-57.

25. Xu Y, Goldkorn A. Telomere and telomerase therapeutics in cancer. Genes (Basel). 2016;7(6):1-21.

26. Akincilar SC, Low KC, Liu C y. Quantitative assessment of telomerase components in cancer cell lines. FEBS Lett. 2015;13(9):974-89.

27. Burchett KM, Yan Y, Ouellette MM. Telomerase inhibitor imetelstat (GRN163L) limits the lifespan of human pancreatic cancer cells. PLoS One. 2014;9(1):1-15.

28. Waghorn PA, Jackson MR, Gouverneur V, Vallis KA. Targeting telomerase with radiolabeled inhibitors. Eur J Med Chem. 2016;125:117-29.

29. Jafri MA, Ansari SA, Alqahtani MH, Shay JW. Roles of telomeres and telomerase in cancer, and advances in telomerasetargeted therapies. Genome Med. 2016;8(1):69.

30. Mender I, Gryaznov S, Dikmen ZG, Wright WE, Shay JW. Induction of telomere dysfunction mediated by the telomerase substrate precursor 6-thio-2'-deoxyguanosine. Cancer Discov. 2015;5(1):82-95 